\title{
Lipoma of Guyon's canal causing ulnar neuropathy
}

\author{
Seema Rohilla $\cdot$ Rohtas K. Yadav \\ Dhara B. Dhaulakhandi
}

Received: 31 October 2008/Accepted: 19 April 2009/Published online: 26 May 2009

(C) Springer-Verlag 2009

\begin{abstract}
Lipoma is a benign soft tissue tumor which rarely causes neuropathy. In closed compartments such as Guyon's canal, even small volume loss can lead to compression of nerve. Hence in such areas, even innocuous tumors such as lipomas can cause neuropathy and warrant surgery. We present one such case of ulnar neuropathy caused by lipoma of Guyon's canal.
\end{abstract}

Keywords Lipoma · Guyon's canal · Ulnar neuropathy

\section{Introduction}

Lipoma is a benign pliable tumor composed of mature adipocytes. It is one of the commonest benign tumors, but rarely causes neuropathy. Very few cases of ulnar neuropathy due to lipoma in Guyon's canal have been reported in literature.

\section{Case report}

A 36-year-old female presented with burning pain and diminished sensations along the little finger and ulnar

S. Rohilla · R. K. Yadav

Department of Radiodiagnosis and Imaging,

Pt. B.D. Sharma Post Graduate Institute of Medical Sciences,

University of Health Sciences, Rohtak 124001, Haryana, India

D. B. Dhaulakhandi $(\square)$

Department of Biotechnology and Molecular Medicine,

Pt. B.D. Sharma Post Graduate Institute of Medical Sciences,

University of Health Sciences, Rohtak 124001, Haryana, India

e-mail: BTMM.submissions@gmail.com aspect of the ring finger of right hand for 6 months. On examination, there was a swelling on the hypothenar eminence and fullness of medial aspect of wrist. The swelling was soft but tense. There was atrophy of muscles on hypothenar aspect of hand. The power of the little and ring fingers was diminished.

Conduction velocity studies of the right ulnar nerve showed prolonged distal motor latency from the wrist to the abductor digiti minimi of $8 \mathrm{~ms}$ (normal $<4.0 \mathrm{~ms}$ ), diminished motor conduction velocity of the ulnar nerve in the elbow-to-wrist segment of $42 \mathrm{~m} / \mathrm{s}$ (normal $45-75 \mathrm{~m} / \mathrm{s}$ ), and prolonged distal sensory latency of $4.2 \mathrm{~ms}$ (normal $<3.5 \mathrm{~ms}$ ). Conduction velocity studies of the left ulnar nerve were normal.

Ultrasound of the swelling showed a well-defined echogenic mass in the hypothenar eminence. Subsequent magnetic resonance imaging (MRI) showed a well-defined lobulated mass hyperintense on both $\mathrm{T} 1 \mathrm{~W}$ and $\mathrm{T} 2 \mathrm{~W}$ images and suppression of signal on STIR images s/o fat (lipoma) (Fig. 1a-c). The mass was lying within the lateral aspect of abductor digiti minimi muscle. Part of it was insinuating between flexor tendons of the hand and metacarpals and another part was insinuating into zones 1 and 2 of Guyon's canal (ulnar tunnel). The mass also extended distally for a considerable distance along the deep branch of the ulnar nerve. The ulnar nerve was stretched over the mass in zone 2 . The carpal tunnel was displaced radially (Fig. 2a, b).

The patient was subsequently operated and the mass was removed. Histopathology showed mature adipose tissue consistent with lipoma. Postoperative course was uneventful with progressive resolution of symptoms and good functional recovery.

The patient provided consent for the publication of this case report. 

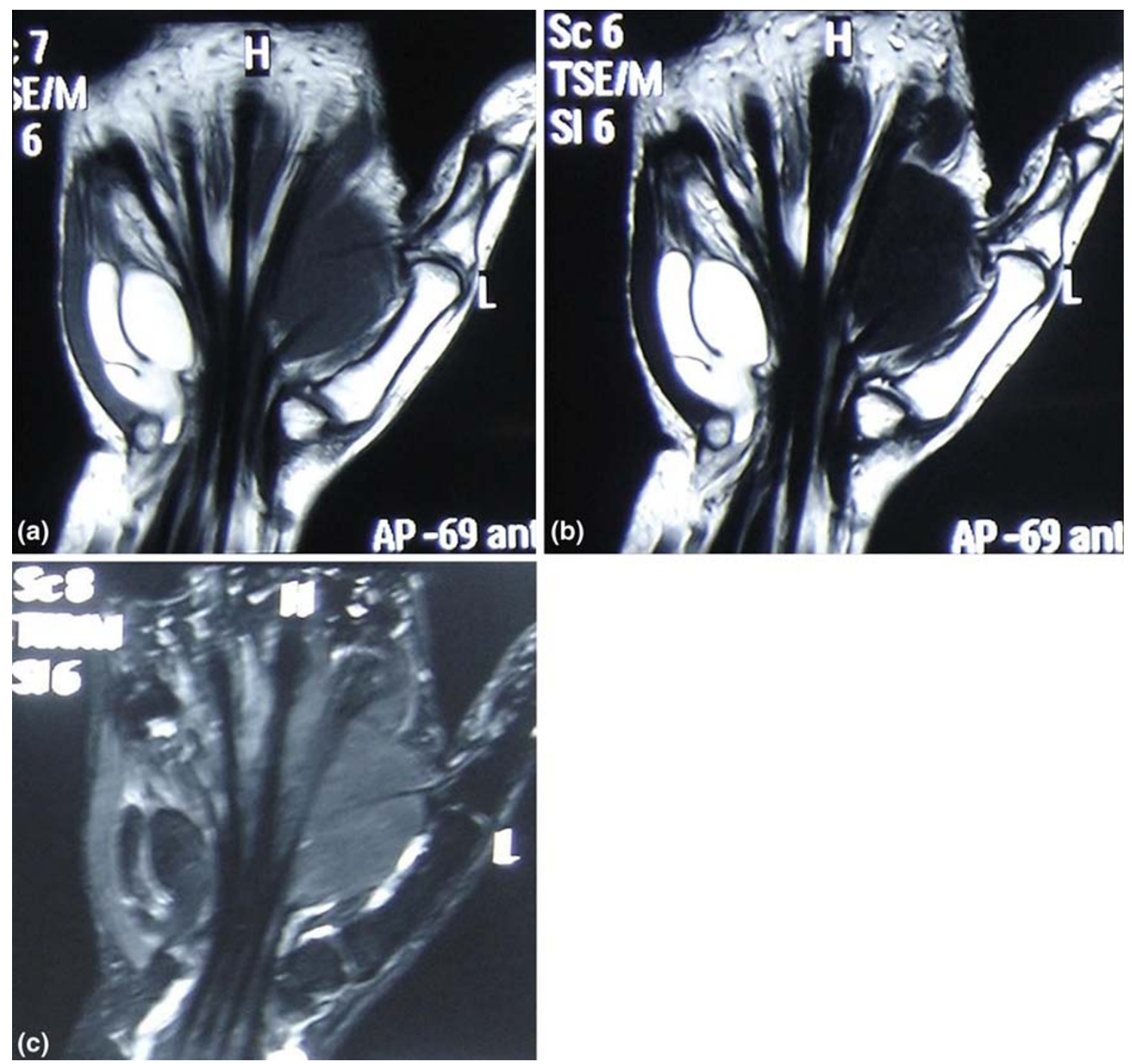

Fig. 1 a T1W coronal images of hand showing a hyperintense mass in the region of hypothenar eminence and along medial aspect of hand. b The mass is hyperintense on T2W images. c The mass shows suppression of signal on STIR images

Fig. 2 a Ulnar nerve stretched by lipoma in zone 2 (arrow). b Lipoma extending distally into the wrist along the deep branch of ulnar nerve
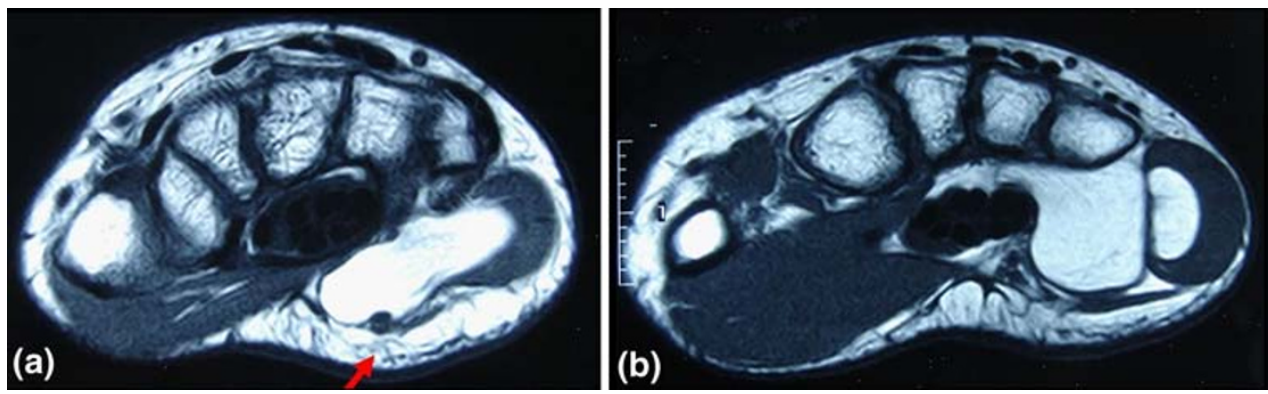

\section{Discussion}

Guyon's canal (ulnar tunnel) is a fibroosseous tunnel along the anteromedial portion of the wrist that contains the ulnar nerve and artery. It extends from the palmar carpal ligament at the proximal edge of the pisiform bone to the origin of the hypothenar muscles at the level of hamulus [1]. The importance of the tunnel lies in the fact that it is a closed compartment and any compromise in its volume can lead to ulnar nerve compression causing Guyon's canal syndrome.

Guyon's canal consists of three zones. Zone 1 is the portion of the tunnel proximal to the bifurcation of the 
ulnar nerve. Zone 2 encompasses the deep motor branch of the nerve which is bounded superficially by the tendinous arcade and deeply by the pisohamate ligament. Zone 3 surrounds the superficial branch consisting mainly of sensory fibres [2]. Clinical symptoms correlate with the zone in which ulnar nerve compression occurs: combined motor and sensory deficits occur in zone 1 lesion, pure motor deficits in zone 2 lesions, and isolated sensory deficits in zone 3 lesions [3]. Our patient had both sensory and motor ulnar neuropathies as there was compression in zone 1 and also zone 2 .

Compressive neuropathies of the ulnar nerve occur mostly at elbow and less commonly at wrist [4]. Various causes of ulnar nerve compression at wrist include ganglion, trauma, giant cell tumors, neurofibromas, intraneural cysts, anomalous muscles, thrombosis, bursitis, and thickened pisohamate ligament $[2,3]$. Other rare causes of ulnar nerve compression are lipoma [2], calcinosis in scleroderma [5, 6], localized nodular synovitis [7], uremic tumoral calcinosis [8], following venipuncture [9], aneurysm of ulnar artery [10], diffuse intramuscular hemorrhage [11], and arteriovenous malformation [12]. Lipoma is a rare cause of neuropathy [13]. To the best of our knowledge, only five cases of ulnar neuropathy due to lipoma in Guyon's canal have been reported to date. This is the sixth case.

Lipoma is a soft tumor and does not normally compress surrounding structures, but even it can cause compression when occurring in a closed compartment such as ulnar tunnel. Timely surgical removal can be curative in such cases.

Conflict of interest statement The authors declare that they have no conflict of interest related to the publication of this manuscript.

\section{References}

1. Gross MS, Gelberman RH (1985) The anatomy of the distal ulnar tunnel. Clin Orthop 196:238-247

2. Sakai K, Tsutsui T, Aoi M, Sonobe H, Murakami H (2000) Ulnar neuropathy caused by a lipoma in Guyon's canal-case report. Neurol Med Chir (Tokyo) 40:335-338

3. Bui-Mansfield LT, Williamson M, Wheeler DT, Johnstone F (2002) Guyon's canal lipoma causing ulnar neuropathy. AJR 178:1458

4. Posner MA (2000) Compressive neuropathies of the ulnar nerve at the elbow and wrist. Instr Course Lect 49:305-317

5. Thurman RT, Jindal P, Wolff WF (1991) Ulnar nerve compression in Guyon's canal caused by calcinosis in scleroderma. J Hand Surg Am 16(4):739-741

6. Chammas M, Meyer zu Reckendorf G, Allieu Y (1995) Compression of the ulnar nerve in Guyon's canal by pseudotumoral calcinosis in systemic scleroderma. J Hand Surg Br 20(6):794796

7. Budny PG, Regan PJ, Roberts AH (1992) Localized nodular synovitis: a rare cause of ulnar nerve compression in Guyon's canal. J Hand Surg Am 17(4):663-664

8. Garcia S, Cofan F, Combalia A, Campistol JM, Oppenheimer F, Ramon R (2000) Compression of the ulnar nerve in Guyon's canal by uremic tumoral calcinosis. Arch Orthop Trauma Surg 120(3-4):228-230

9. Radji M, Zaarour J, Lhotellier F, Zakine J, Aihonnou T (2008) Ulnar neuropathy following venipuncture. Ann Fr Anesth Reanim 27(1):114-115

10. Yoshii S, Ikeda K, Murakami H (1999) Ulnar nerve compression secondary to ulnar artery true aneurysm at Guyon's canal. J Neurosurg Sci 43(4):295-297

11. Vijayakumar R, Nesathurai S, Abbott KM, Eustace S (2000) Ulnar neuropathy resulting from diffuse intramuscular hemorrgahe: a case report. Arch Phys Med Rehabil 81(8):1127-1130

12. Ozdemir O, Calisaneller T, Altinors N (2000) Compression of the ulnar nerve in Guyon's canal by an arteriovenous malformation. J Hand Surg Eur 32(5):600-601

13. Galeano M, Colonna M, Risitano G (2001) Ulnar nerve syndrome secondary to lipoma of the hypothenar region. Ann Plast Surg 46(1):83-84 